\title{
REPÚBLICA Y EXILIO ESPAÑOL EN EL FIN DEL MUNDO. VALPARAÍSO, CHILE ${ }^{1}$
}

POR

BALDOMERO ESTRADA TURRA

Pontificia Universidad Católica de Valparaíso

En este artículo nos interesa mostrar las repercusiones que tuvo la experiencia republicana española en la colectividad migrante, de esa nacionalidad, en Valparaíso (Chile). Así como analizar el proceso de adaptación e integración del grupo de exiliados españoles que llegó a esta ciudad, luego de terminada la guerra civil en su país de origen.

Palabras Clave: República, inmigración, exilio, adaptación, integración.

\section{INTRODUCCIÓN}

El proceso vivido por la pequeña colectividad de españoles residentes en Valparaíso, a partir de la década de $1930^{2}$, es interesante por cuanto se reconstruye en un lugar muy distante, un escenario político ideológico propio de España, pero impropio de un colectivo constituido por una mayoría de comerciantes que llevaban muchos años alejados de su tierra, y que se habían caracterizado por su desinterés en los acontecimientos de la patria de origen ${ }^{3}$. La

1 Este trabajo es parte del proyecto FONDECYT N. ${ }^{\circ} 1050326$.

2 Según censo poblacional de 1930, la colectividad española de Valparaíso era de poco más de 3.000 habitantes, siendo el grupo europeo más numeroso de la ciudad.

3 El cónsul español en Valparaíso, Antonio Alcalá Galiano, en 1888, describía a la colectividad en los siguientes términos: «Periódicos españoles no hay aquí ni el número de compatriotas lo requiere, ni hay quien los redacte ni menos quien los lea. A duras penas se ve ojear los pocos que recibe el Club y salvo la parte mercantil de los de la localidad, no suelen los españoles dedicarse a saber lo que pasa por el mundo ni a enterarse con mucho interés de los detalles de la existencia ordinaria de España. Los grandes acontecimientos prósperos o adversos de esos si los conmueve en general profundamente pero a la marcha política de la nación de que se 
presencia, primero de pequeños grupos de asilados franquistas y luego de exiliados republicanos, que llegaron a Chile en un número cercano a los 3.500. y de los cuales unos 700 se establecieron en Valparaíso, estimuló la división interna entre los miembros de la colectividad, presionándolos a definirse entre los bandos en disputa y que se expresó en la lucha por el control de las instituciones de la colectividad. Por consiguiente, a diferencia de otros lugares, como México y Argentina, en donde también arribaron exiliados y se produjeron conflictos, la confrontación entre ambos bandos, en Chile, comenzó desde antes de la llegada de los exiliados. La diferencia con los otros países surge del desembarco de españoles franquistas que llegaron al país luego de asilarse en la embajada chilena en Madrid. La excepcional conducta de Chile respecto a la mayoría de los países, en cuanto a aplicar el derecho de asilo, repercutió directamente en la situación interna de la colectividad española en Chile, generando un escenario de mayor actividad política. La posterior llegada de exiliados republicanos sólo consolidó una situación que ya estaba construida.

La presencia de los asilados fue reducida y sólo temporal por cuanto mayoritariamente regresaron a España una vez consolidado el triunfo de Franco. Sin embargo, la situación de los exiliados fue muy diferente. Si bien sus intenciones eran de permanecer por poco tiempo, las circunstancias determinaron algo muy diferente. La condición de exiliados generó en ellos y sus familias una situación de inestabilidad que hizo más difícil su proceso de integración, tanto con su propio colectivo, como también con la sociedad receptora. De allí que nos resulte importante poder analizar la situación que se produjo en la ciudad, al interior de la colectividad, durante los años que imperó la República en España y luego, especialmente a través de los testimonios orales de quienes pertenecen al colectivo, poder aproximarnos a las circunstancias sociales y espirituales que conformaron el ambiente de vida de los exiliados en Valparaíso. Nos parece fundamental poder aproximarnos a una faceta humana todavía rescatable e importante para reconstruir parte de la historia de la inmigración española y del exilio, poco conocida en nuestro país, que tiene que ver con la historia local de la ciudad de Valparaíso, de España, pero sobre todo es parte de un fenómeno universal siempre presente en la historia de la Humanidad.

Resulta novedoso advertir la fuerza que manifestó el bando republicano previo a la llegada de los exiliados, en razón de la escasa inquietud que la co-

hallan separados por tan larga distancia le prestan poca o ninguna atención. Así es que si hay aquí españoles que se proclaman republicanos, liberales, conservadores o carlistas, es lo cierto que lo son platónicos y rara vez se les ve preocuparse de otra cosa que de atender a sus negocios», Informe del cónsul, Archivo General de la Administración (Alcalá de Henares), (AGA) Legación Chile, Caja 9288. 
lectividad había mostrado anteriormente por los temas políticos. Una de las causas que pueden explicar la fuerza que tuvo el republicanismo en Valparaíso puede encontrarse en la fuerte presencia de vascos y catalanes, quienes apelaron a su identidad regional para oponerse a los ideales franquistas.

El proceso político español y su impacto en Chile debemos también analizarlo teniendo especial cuidado de incluir los acontecimientos políticos nacionales, por cuanto el término de la guerra civil española coincide con el inicio en Chile de un gobierno del Frente Popular (1938), que facilitó la venida de refugiados republicanos. Difícilmente el régimen anterior, de Arturo Alessandri, habría tenido tal actitud, que, por el contrario, se mostró muy condescendiente con el bando franquista a través de la concesión del asilo, trayendo a algunos de ellos a nuestro país y apoyando embozadamente sus actividades proselitistas.

Por lo demás, la guerra civil española sabemos que se inserta en la dinámica de un conflicto internacional mucho mayor, efecto de un proceso de violencia que arrastró a Europa por muchos años y que caracterizó al período comprendido entre 1850 y 1950 como el más sangriento de la Humanidad, que se tradujo en la muerte de millones de seres humanos y con impactantes consecuencias para quienes quedaron vivos ${ }^{4}$. En dicho período emigraron de Europa más de 50 millones de personas. Algunos por problemas económicos, otros por temor a ser llevados a la guerra y otros como consecuencia de los desastres ocasionados por ésta. Si bien, la segunda mitad del siglo XX, se caracterizó por la guerra fría bien sabemos que culminó con los casos de enfrentamientos étnicos más salvajes que pueda reconocer la historia. Los conflictos tribales africanos y la desintegración de Yugoslavia son un vergonzoso testimonio de lo que puede ser la miseria humana. Como consecuencia de esos conflictos son miles los individuos que han tenido que dejar su hogar ver destruida su identidad, sus familias y verse obligados a huir a cualquier lugar.

La llegada de la nave francesa «Winnipeg» a Chile en septiembre de 1939 constituyó un importante hito en la hégira hispana republicana y se inserta en un proceso macro social. De los cerca de 2.300 pasajeros que trajo la nave, 650 de ellos se quedaron en Valparaíso ${ }^{5}$. De ese grupo, muchos reemigraron, algunos regresaron a España, otros han muerto. En todo caso, aún queda un

${ }^{4}$ Hobsbawm, 1996, define el período comprendido entre 1914 hasta fines de la Segunda Guerra Mundial como una época de catástrofes.

5 Según documento del Comité Chileno de Ayuda a los Refugiados Españoles con fecha 1 de octubre de 1939 se quedaron en Valparaíso 650 exiliados (originalmente se quedarían 600) de los cuales, a la fecha indicada, se encontraban ubicados 550, Archivo General de la Administración (Alcalá de Henares), Legación Chile, Legajo 9349. Entre las obras escritas sobre el «Winnipeg»: Ferrer Mir, 1989. Carcedo, 2006. Palacios, 1939. 
segmento de ese grupo, no pocos de los cuales llegaron muy jóvenes, quienes, conjuntamente con los descendientes de algunos que ya partieron, aún permanecen en la ciudad. Su historia es un testimonio vivo de lo que significa el exilio como experiencia de inmigración forzada, marcando un hito importante de lo que han sido las secuelas dramáticas de los enfrentamientos internos que afectan a las naciones.

Al referirnos al proceso inmigratorio de los republicanos españoles en Valparaíso estamos haciendo historia local en cuanto a los efectos que tal experiencia tuvo para la sociedad receptora, pero, por otro lado, este caso no es sino un ejemplo de un fenómeno mundial. Es decir, estamos también conociendo un fenómeno que ha afectado a millones de personas a través de siglos y en toda la amplitud de la Humanidad.

Son muchas las preguntas que pueden surgir como inquietud científica frente al fenómeno del exilio. Nuestro interés se centra en conocer la relación que establecen los exiliados con la sociedad receptora y los lazos que mantienen con la de origen. A diferencia de quienes emigran sin verse forzados, a la manera de los exiliados, estos últimos cargan con sentimientos de culpa por el fracaso político, y viven el «síndrome de las maletas listas» para el retorno, lo cual retarda la adaptación al medio receptor.

A base de testimonios escritos y, sobre todo, de entrevistas a algunos sobrevivientes, y descendientes de éstos, haremos un análisis de lo que el proceso de exilio ha significado para este grupo de españoles que llegaron a Valparaíso. Ciudad que, finalmente para ellos, pasó a ser parte fundamental en sus vidas.

Los más de treinta años que se mantuvo en el poder Franco prolongaron los deseos de retorno para muchos que no pudieron, o no quisieron hacerlo, mientras el dictador se mantuvo en el poder. Algunos murieron antes y otros ya no lo consiguieron, o, simplemente no tuvieron los deseos de volver.

\section{LA EMBAJADA DE ChILE EN MADRID Y EL DERECHO DE ASILO}

El papel desempeñado por la embajada chilena una vez declarada la guerra, en julio de 1936, fue fundamental en cuanto al derecho de asilo que se aplicó en esa ocasión, generando una situación que reforzó una institución, incorporada por los países latinoamericanos, pero que no era aceptada en forma general como en el caso de Estados Unidos, URSS y Gran Bretaña, entre otros. El conflicto se inició en julio, pleno verano, cuando muchas embajadas, especialmente latinoamericanas, se encontraban cerradas, lo que determinó que algunos embajadores y cónsules no regresaran a hacerse cargo de sus se- 
des diplomáticas. Los refugiados se concentraron en las de Alemania, Checoslovaquia y entre las latinoamericanas, las de Argentina, Uruguay, Colombia, México, Perú y Chile, siendo esta última la que acogió el mayor número de asilados. Incluso, nuestra embajada, posteriormente se hizo cargo de los que se encontraban en el recinto de la alemana e italiana, que terminaron reconociendo al gobierno de Franco. Lo mismo ocurrió con los asilados de países que rompieron relaciones con el gobierno republicano, como por ejemplo, Perú y El Salvador 6 .

Al inicio del conflicto cumplía las funciones de embajador chileno Aurelio Núñez Morgado, quien desde el primer momento, por razones humanitarias y al parecer estimulado por su postura política inclinada a favor del bando nacionalista, aplicó el derecho de asilo, pese a las instrucciones que se le enviaban desde Santiago. La amenaza de ser declarado persona non grata aceleró su regreso, en abril de 1937, dejando a cargo de la embajada a Carlos Morla Vicuña, en calidad de encargado de negocios ${ }^{7}$.

Los enfrentamientos en Madrid transformaron a la embajada de Chile en uno de los lugares de mayor demanda por parte de partidarios de los nacionalistas, llegando a reunir a más de 2.000 personas bajo su protección, debiendo pasar por muchas peripecias hasta el término del conflicto. Negociaciones diplomáticas para convencer a las autoridades republicanas sobre la aplicación del derecho de asilo, provisión de alimentos y espacios físicos que salvaguardaran la seguridad de los refugiados en medio de enfrentamientos, fueron parte de los problemas que tuvo que enfrentar la diplomacia chilena, especialmente Carlos Morla Lynch, a quien le correspondió responsabilizarse de la situación durante la mayor parte del período ${ }^{8}$. De la parte seguridad y provisión de alimentos era responsable el Teniente Coronel Humberto Luco quien debía ingeniárselas para obtener alimentos para los asilados en los pueblos cercanos en cantidades reducidas por cuanto el Gobierno republicano sólo permitía el ingreso a Madrid abastecimiento para el personal de la sede diplomática (cinco personas) y consideraba a los asilados enemigos de la República9 .

Luego del triunfo de las fuerzas nacionalistas nuestra embajada acogió también a refugiados de las fuerzas republicanas derrotadas, con lo cual hubo de enfrentar una nueva difícil situación diplomática, ahora con el régimen nacionalista. Los argumentos de nuestra Cancillería fueron los mismos que se esgrimieron en la situación anterior.

6 Nocera, 2006: 35-36.

7 Vargas, 2003: 26.

8 Morla Lynch, 2003.

9 El Mercurio de Valparaíso (Valparaíso, 6 de abril de 1938): 1. 
Debemos recordar que para el período del conflicto hispano se produjo en nuestro país un interesante proceso de cambios internos como lo fue la asunción del poder político por parte de una coalición izquierdista encabezada por el radical Pedro Aguirre con apoyo de comunistas y socialistas, que reemplazó al gobierno de Arturo Alessandri apoyado fundamentalmente por partidos de derecha. En todo caso, frente a la crisis española se manifestó una sólida y uniforme política en procura de respetar los principios expuestos, por la Cancillería chilena respecto al derecho de asilo, que no se alteraban ante los avatares políticos internos. «Así se demostró que una política exterior definida externamente por el apego a la ley, cuando se la sigue de manera consistente, sirve como brújula en un mar embravecido en el que no hay garantía de arribar» ${ }^{10}$.

\section{LA COLECTIVIDAD ESPAÑOLA EN CHILE Y LA REVOLUCIÓN}

A comienzos de 1937 el Consulado español de Valparaíso vivía un elocuente período de inactividad. El vicecónsul encargado Téllez hacía notar en un informe al ministro de Estado en Valencia, el notorio descenso que había tenido el Consulado en el segundo semestre de 1936. Señalaba como causales la situación político-social de España; supresión del movimiento inmigratorio desde España; escaso intercambio comercial y críticas circunstancias económicas del país que habían obligado a muchos españoles a reemigrar ${ }^{11}$. De hecho, en los dos primeros meses del año 1937, 15 personas solicitaron pasaporte o visa para dirigirse mayoritariamente a Argentina ${ }^{12}$.

Consideraba el diplomático que era predecible que, en un futuro, aunque mejoraran las circunstancias, no habrían de haber modificaciones sustantivas por lo que sugería que podía reducirse la plantilla de personal de carrera, ya que consideraba excesivo y gravoso para el presupuesto nacional la situación existente ante las circunstancias y perspectivas futuras. Proponía la supresión del vicecónsul y la reducción de los haberes del cónsul a una cantidad análoga a la de otros cónsules acreditados en la ciudad ${ }^{13}$.

\footnotetext{
10 Fermandois, 2004: 132.

11 Comunicación del Vicecónsul Encargado al Ministro de Estado en Valencia, Valparaíso, 16 de enero de 1937, Archivo de la Fundación Universitaria Española de Madrid, Ch 25-1.

12 Relación de pasaportes otorgados y visados efectuados por el Consulado General de España en Valparaíso desde el 1 de enero del corriente hasta el 9 de marzo, Valparaíso, 9 de marzo de 1937, en: Archivo de la Fundación Universitaria Española de Madrid, Ch 25-1. De los 15 solicitantes 13 se dirigían a Argentina, uno a Perú y uno a Panamá.

13 Comunicación del Vicecónsul Encargado al Ministro de Estado en Valencia, Valparaíso, 16 de enero de 1937, Archivo de la Fundación Universitaria Española de Madrid, Ch 25-1.
} 
Para entonces el vicecónsul ya se mostraba molesto por la actitud de determinado sector de la colectividad por lo cual sugería ciertas medidas que deberían tomarse llegado el momento sosteniendo que «una vez terminada victoriosamente para nuestra causa la parte militar de la guerra y reorganizado sobre nuevas bases el Estado español habrá que dilucidar el estatuto jurídico de los ciudadanos españoles aquí residentes que en su mayoría han hecho profesión de fe facciosa y a los cuales supongo que habrá que sancionarles con la pérdida de la nacionalidad» ${ }^{14}$.

La posición internacional de Chile permitió, en 1936, la llegada de un grupo de refugiados nacionalistas, algunos de los cuales tuvieron una participación destacada en la agitación política partidaria al interior de la colectividad española. La prensa local informaba, en octubre de ese año, de la llegada, a bordo del «Virgilio», de más de un centenar de repatriados españoles y chilenos llegados de España huyendo de los horrores de la guerra ${ }^{15}$. En junio de 1937 llegaron a Valparaíso, a bordo del «Orduña», 51 refugiados nacionalistas desde la embajada chilena en Madrid. Fueron recibidos por el jefe del Departamento Consular y una delegación de la Junta Nacionalista de Santiago. La prensa local publicó los nombres y oficios de los recién llegados e informó que todos ellos se habían comprometido, por escrito, a no hacer declaraciones ni participar de ninguna actividad política. De acuerdo a la misma fuente, los refugiados serían ubicados ente Santiago y Valparaíso en donde ya se contaba con instituciones y empresas que estaban dispuestas a incorporarlos en sus plantas laborales ${ }^{16}$. En todo caso, la venida de nacionalistas fue muy reducida y no tuvo, en ningún caso, la importancia y el impacto que provocó la llegada de los refugiados republicanos que comenzaron a llegar a partir de 1938 .

Entretanto se había producido un enfrentamiento entre el Consulado General y la Cámara de Comercio Española de Chile, cuya sede estaba en Valparaíso. El 19 de febrero de 1937 salió publicado un aviso del Consulado General de España, en varios periódicos, informando que por decisión del Ministerio de Industrias y Comercio español se suspendían todas las actividades de la «Cámara Oficial Española de Comercio en Chile», hasta que se efectuara su reorganización sobre nuevas bases ${ }^{17}$.

La respuesta de la Cámara de Comercio al vicecónsul encargado, fue que, esta institución, era una entidad de carácter privado y que en la administración

14 Idem.

15 El Mercurio de Valparaíso (Valparaíso, 16 de octubre de 1936): 4.

16 El Mercurio de Valparaíso (Valparaíso, 2 de junio de 1937).

17 Inserción del Consulado General de España en Valparaíso en El Mercurio de Valparaíso, 16 de febrero de 1937. 
de la Cámara no tenía ingerencia alguna, ningún representante del Gobierno español por cuanto sólo les correspondía a la representación diplomática los honores de presidir sus reuniones cuando asistieran ${ }^{18}$. A estos argumentos el Vicecónsul replicó que tal afirmación de privacidad de la institución era falsa, por cuanto las Cámaras de Comercio recibían subvención gubernamental, debían ser reconocidas oficialmente y sus propios estatutos establecían vínculos de dependencia oficial ${ }^{19}$.

En un comunicado posterior dirigido por el vicecónsul al embajador R. Soriano se informa que el tema de la Cámara ha quedado plenamente resuelto habiendo nombrado la directiva, sosteniendo que había logrado la adhesión de un sector importante de comerciantes solventes y respetables que estaban dispuestos a dar su apoyo a la causa republicana. Luego de este panorama, el diplomático concluía que «de esta manera los facciosos además de una paliza tienen que enfrentarse con dos enemigos, el Consulado y la Directiva legítima y oficial de la institución. No van a tener fuerzas ni atreverse a tanto ${ }^{20}$.

Dentro de un ambiente aparentemente tranquilo comenzaron a realizarse una serie de actividades, de ambos bandos, de proselitismo encubierto al principio para pasar luego a un proselitismo desembozado, especialmente de los nacionalistas, sobre todo cuando la guerra civil en España se encontraba en un punto de incertidumbre que no garantizaba la estabilidad del republicanismo.

A mediados de marzo de 1937 aparece «un grupo de damas de nuestra sociedad» invitando a un almuerzo para ir en ayuda de los niños huérfanos y desamparados como consecuencia de la guerra civil española. Entre las convocantes aparecían damas que no pertenecían a la colectividad como otras que sí lo eran. Entre las últimas sobresalían la esposa y nuera del ex cónsul Mariano Fábregas ${ }^{21}$.

Cuatro meses más tarde se organizó, en el Salón Alemán del Cerro Alegre, un gran almuerzo para ir en ayuda de los huérfanos y mutilados en la guerra, organizado por la Junta Nacionalista y la Falange Española Tradicionalista de las JONS en el día de Santiago de Compostela, patrono de España ${ }^{22}$.

Fue un gran evento al cual asistieron grupos falangistas de Santiago y otras ciudades cercanas que sumaron alrededor de 300 personas. Al respecto, El Mercurio de Valparaíso, que cuantificó la asistencia total en «no menos de un

18 El Mercurio de Valparaíso (Valparaíso, 19 de febrero de 1937).

19 El Mercurio de Valparaíso (Valparaíso, 20 de febrero de 1937).

20 Comunicación del vicecónsul Salvador Téllez al embajador Rodrigo Soriano, 23 de febrero de 1937, Archivo de la Fundación Universitaria Española de Madrid, CH 25-1.

21 El Mercurio de Valparaíso (7, 11 y 12 de marzo de 1937).

22 El Mercurio de Valparaíso (20 y 26 de julio 1937). 
millar», informaba que «todas estas personas llegaron en el expreso de la mañana y fueron objeto de una cariñosa recepción en los andenes de la estación Puerto de donde siguieron en correcta formación hasta el centro de la ciudad dirigiéndose muchos al local del Centro Español». Entre las personalidades asistentes se encontraban el encargado de negocios del gobierno de Burgos, Joaquín Pérez de Rada; el jefe de la Falange Española Tradicionalista Miguel María de Lojendio, Presidente de la Junta Nacionalista de Valparaíso. A la hora de los discursos, además de las autoridades mencionadas participaron también un sacerdote repatriado y el ex cónsul Mariano Fábregas quien homenajeó al general Mola a quien calificó de héroe ${ }^{23}$.

El vicecónsul Téllez de inmediato informó a su embajador del evento adjuntándole recortes de la prensa local que se referían a la reunión-almuerzo en cuestión. Hizo notar la presencia del cónsul alemán y la relevante cobertura que le dio la prensa, aunque calificó el encuentro como nada extraordinario. Igualmente hizo notar la asistencia de los jefes del partido nazi alemán y la participación de dos ex refugiados, Joaquín Calvo Sotelo y el sacerdote P. Bueno ${ }^{24}$.

Para el 12 de octubre se realizó, por parte de la Falange Española Nacionalista, una fiesta en el Teatro Victoria que contó con la presencia de representantes consulares de Alemania, Italia y Portugal. El programa comprendía una alocución a cargo del escritor Humberto Bórquez, entonación de himnos patrios de Chile y España y la puesta en escena de una zarzuela ${ }^{25}$. En ese mismo mes y como parte de las celebraciones del día de la raza, en una ceremonia en la iglesia del Inmaculado Corazón de María, se bendijeron tres banderas que la sección femenina obsequió a la Falange Española Tradicionalista de Valparaíso. Se trataba de las banderas chilena, española y de la Falange ${ }^{26}$.

Otro frente importante por el cual actuaban los falangistas fueron las conferencias para lo cual contaban con figuras políticas venidas expresamente de España, algunos refugiados o dirigentes locales que sobresalían como agitadores o activistas. En octubre de 1937 la prensa local informaba de una conferencia del ex refugiado español en la embajada chilena en Madrid, Joaquín Calvo Sotelo titulada «Al Amparo de las Banderas de América», que se refería específicamente a la vida de los asilados en las embajadas acreditadas en Madrid. Frente a este anunció el vicecónsul informó de inmediato a su embajada en

23 Idem.

24 Comunicación del Vicecónsul Téllez al embajador, Valparaíso, 26 de julio de 1937, Archivo de la Fundación Universitaria Española de Madrid, CH 25-1.

25 Diario La Unión (Valparaíso, 9, 11, 12 y 13 de octubre de 1937).

26 Diario La Unión (Valparaíso, 19 de octubre de 1937): 6. 
Santiago haciendo ver que tal noticia «ha producido viva inquietud en la colonia española que ha acudido a mí en sentido de protesta por la tolerancia dispensada para esta clase de actos de tendencia subversiva, máxime cuando son sus actores personas sobre las que pesan compromisos solemnes de abstención, cuyo cumplimiento está garantizado por el Gobierno de Chile, gracias a los cuales les fue concedida la evacuación». El diplomático agregaba que días antes, el 3 de octubre, la autoridad regional había suspendido una conferencia del escritor chileno Alberto Romero (partidario de los republicanos), sobre su estadía en España, dando como explicación de su medida que para ese mismo día se realizaría también un acto en el que participaría Joaquín Calvo Sotelo ${ }^{27}$.

Los comentarios del diplomático dejaban muy en claro que el intendente provincial tenía una abierta actitud protectora del bando nacionalista, que, por lo demás, coincidía con la postura del gobierno de Arturo Alessandri en su política nacional e internacional frente al conflicto hispano.

En noviembre de 1937 se informaba que intelectuales enviados por Franco nos visitaban para dictar conferencias. Se trataba de José María Ibáñez, Juan Pablo Lojendio y Eugenio Montes. José Ibáñez realizó una presentación en la Universidad Católica de Valparaíso sobre los ideales de España. Al día siguiente, en el Teatro Real dio una conferencia Eugenio Montes y, finalmente, en el Teatro Imperio intervino Juan Pablo de Lojendio para referirse a la finalidad que tenía el movimiento nacionalista español explicando la situación de España antes de la revolución y lo que se pensaba hacer con la nación de acuerdo con los principios nacionalistas ${ }^{28}$. Al mes siguiente, otro enviado de Franco, Gonzalo Valenti Nieto, jefe de la Misión Extraordinaria enviada a Sudamérica, expuso sobre «Lo Mítico y Heroico de la Guerra de España» ${ }^{29}$. En esa misma semana, el senador chileno Maximiano Errázuriz dio una conferencia en la Universidad Católica de Valparaíso dando una visión del estado de España a partir de un viaje que había realizado a ese país, ocasión en que tuvo la oportunidad de entrevistarse con Franco, quien manifestó que «el carácter de su movimiento era combatir la implantación en España del régimen comunista». Agregó que España había sido siempre un baluarte de la civilización cristiana occidental habiendo combatido a los moros, a los turcos y había conquistado América para la civilización cristiana ${ }^{30}$.

27 Comunicación del Vicecónsul Salvador Téllez a la Embajada de España en Chile, Valparaíso, 13 de octubre de 1937, Archivo de la Fundación Universitaria Española de Madrid, CH 25-1.

28 Diario La Unión (Valparaíso 5, 6, 7, 8, 9 y 10 de noviembre de 1937).

29 Diario La Unión (Valparaíso, 13 de noviembre de 1937): 6.

30 Diario La Unión (Valparaíso, 15 de noviembre de 1937). 
Por su parte, los republicanos también realizaban sus propias actividades proselitistas aunque no tenían la misma cobertura de la prensa local cuya ideología se identificaba de modo más claro con el nacionalismo franquista, especialmente en el caso del diario La Unión, ya que respecto a El Mercurio de Valparaíso, si bien se percibía apoyo hubo también situaciones conflictivas sobre todo a partir de artículos críticos acerca de la situación económica y cultural de España.

Sin embargo, se contaba con el apoyo de prensa capitalina como por ejemplo, entre los de mayor difusión, el diario La Hora y La Opinión. En junio de 1937 el embajador Soriano enviaba un comunicado a la colectividad porteña informándoles que dos periodistas de La Hora, Agustín Rodríguez y Alfonso de la Barra, viajarían a Valparaíso para reunir materia a fin de incluir en un número especial de aniversario información en apoyo a la causa republicana ${ }^{31}$. Posteriormente, el embajador informó que para el 12 de octubre el diario $L a$ Opinión sacaría un número especial dedicado a España ${ }^{32}$.

Entre las actividades desarrolladas por los republicanos sobresale la recolección de alimentos para ser enviados a España. Es el caso de la campaña llevada a efecto por la Unión Republicana de Valparaíso que efectuó una serie de acciones y actividades para adquirir leche condensada para los niños españoles. Entre otras instituciones participaban además el Comité Patriótico Catalán, el Comité Vasco, la Asociación de Amigos de España y la Liga para la Defensa de los Derechos del Hombre ${ }^{33}$. Para el mes de julio de 1937 ya se habían realizado dos envíos de alimentos por parte de los republicanos. Una de las actividades realizadas correspondía a una kermés efectuada el 14 de abril en conmemoración de la instauración de la República ${ }^{34}$. El resultado había sido el envío de víveres y ropa vía Francia contando con la colaboración de Camilo Peduran, cónsul de ese país, para tal efecto ${ }^{35}$.

Las conferencias fueron también otra vía de concientización a la que recurrieron los opositores al franquismo. En diciembre de 1937 se hizo presente en

31 Comunicado del embajador Rodrigo Soriano a la colectividad española de Valparaíso, 11 de junio de 1937, Archivo de la Fundación Universitaria Española de Madrid, CH 24-3.

32 Comunicado del embajador Rodrigo Soriano a la colectividad española de Valparaíso, 28 de septiembre de 1937, Archivo de la Fundación Universitaria Española de Madrid, CH 24-3.

33 Comunicado del Vicecónsul Encargado Salvador Tellez, Embajador de España, Valparaíso 8 de julio de 1937, Archivo de la Fundación Universitaria Española de Madrid, CH 25-1.

34 Comunicado del Vicecónsul Encargado Salvador Téllez, Embajador de España, Valparaíso 9 de junio de 1937, Archivo de la Fundación Universitaria Española de Madrid, CH 25-1.

35 Nota de agradecimiento del embajador de España a Camilo Peduran, cónsul de Francia en Valparaíso, 26 de junio de 1937, Archivo de la Fundación Universitaria Española de Madrid, CH 24-3. 
el Teatro Valparaíso Pablo Neruda, el escritor argentino Raúl González Tuñón y el diputado y poeta Julio Barrenechea. La velada se clausuró con interpretaciones corales que incluyeron canciones de guerra coreadas por el público ${ }^{36}$. Este acto fue la repetición de otro que se había realizado en Santiago, organizado por la Alianza de Intelectuales de Chile dirigida por Neruda. Otra de las actividades llevadas a cabo fue la exhibición de la película «De Regreso» que había sido prohibida, en principio, por las autoridades nacionales ${ }^{37}$.

En todo caso el conflicto no se debatía solamente al nivel de almuerzos, conferencias, recolección de recursos para huérfanos o kermeses. Paulatinamente se fue produciendo un creciente clima de agresividad que se manifestó en diversos conatos y agresiones físicas.

La llegada de los refugiados nacionalistas marcó un cambio radical al escenario tal como lo denunció el vicecónsul encargado al sostener que al parecer «eran estos quienes alentaban en territorio chileno la rebeldía contra los demás españoles que no comparten su simpatía con el movimiento sedicioso». Aseguraba que hasta ese momento y a pesar de la división existente en la colectividad, no se habían dado manifestaciones tan agresivas como las que comenzaron a producirse con la llegada de los «asilados» produciendo «una tirantez peligrosísima que puede llegar a producir hechos de sangre muchos más lamentablemente y quizás irreparables $\rangle^{38}$. Todas estas reflexiones tenían que ver con un ataque que había sufrido un español de apellido Galán quien fue agredido por la espalda por un grupo entre los cuales se contaban varios asilados, siendo detenido por la policía al menos uno de ellos, Ramón Bonilla, quien se desempeñaba como empleado en el Banco Español de Chile. Hacía notar el diplomático que los «asilados» solían irrumpir en las instituciones españolas en actitud provocativa lanzando insultos, provocando consecuencias como la referida que había terminado en una denuncia en los tribunales correspondientes. Agregaba el vicecónsul que se abstuvo de hacer la denuncia ante el intendente en razón de la conocida adhesión que éste había manifestado por el bando nacionalista pero esperaba que pudieran hacerse algunas gestiones ante las autoridades nacionales a fin de poner coto a la irregular conducta de los asilados ${ }^{39}$.

36 Comunicado del Vicecónsul Encargado al Ministro de Estado en Barcelona, 29 de diciembre de 1937, Archivo del Ministerio de Asuntos Exteriores de Madrid, Legajo R-1000, Expediente 2 .

37 Idem.

38 Comunicación del Vicecónsul Encargado al Embajador de España en Chile, Valparaíso, 15 de junio de 1937, Archivo de la Fundación Universitaria Española de Madrid, CH 25-1.

39 Idem. 
A la semana siguiente nuevamente el Vicecónsul Encargado insistía, ante el embajador, sobre la violencia promovida por los refugiados. Entre éstos señalaba la agresión sufrida por un compatriota, Gabino Sánchez, quien fue insultado y agredido con una botella en la pensión en donde residía por un grupo de falangistas entre los cuales sobresalían dos refugiados, Ricardo Gómez y Ricardo Valle, quienes sacaron revólveres con los cuales encañonaron a la víctima. Un segundo incidente fue provocado por Manuel Fernández, dirigente de Falange Española, quien primero insultó en la calle a su compatriota Eugenio García y luego lo agredió en el Centro Español ante numerosos testigos por el hecho de portar una escarapela de la República española. Estos hechos le fueron, a su vez, denunciados por una comisión de miembros de la colectividad quienes conjuntamente con expresar su protesta querían dejar constancia que «desde ese momento declinaban toda responsabilidad por los hechos lamentables incluso luctuosos que puedan ocurrir en el futuro, de los cuales, como hasta ahora está bien probado, no serían culpables». Agregaban que estaban dispuestos a proceder en legítima defensa respondiendo en forma adecuada las provocaciones y ataques que puedan sufrir en lo sucesivo ${ }^{40}$.

Un nuevo acto de agresión se señalaba como noticia secundaria en otra comunicación del vicecónsul refiriéndose a la agresión que fue víctima un automovilista al que, además, se le arrancó de su vehículo una bandera republicana. Otro grupo había ingresado al local comercial de Adriano Torres agrediendo a uno de sus empleados que se encontraba solo ${ }^{41}$.

No tenemos antecedentes de agresiones provocadas por el bando republicano desde las fuentes disponibles, pero suponemos que deben haber existido también, al menos como respuestas, tal como lo prometió la comisión que visitó al representante consular.

Los días 13, 14 y 15 de febrero de 1937 se realizaron elecciones de directiva en el Centro Español que fueron cuestionadas por algunos socios llegándose a plantear el tema en los tribunales ordinarios. Es así como por sentencia del juzgado local y luego por confirmación de la Segunda Sala de la Corte de Apelaciones se decidió la repetición de la elección del Directorio ${ }^{42}$.

Cabe reiterar que, anteriormente a la elección de 1937, el Centro se había mantenido controlado por sectores que tenían una clara identidad con el bando

40 Comunicación del Vicecónsul Encargado al Embajador de España en Chile, Valparaíso, 21 de junio de 1937, Archivo de la Fundación Universitaria Española de Madrid, CH 25-1.

41 Comunicación del Vicecónsul Encargado al Embajador de España en Chile, Valparaíso, 13 de octubre de 1937, Archivo de la Fundación Universitaria Española de Madrid, CH $25-1$.

42 Diario El Mercurio de Valparaíso (Valparaíso, 25 y 26 de agosto de 1937). 
nacionalista. Pero en la elección de comienzos de ese año la situación había cambiado como también ocurrió con la Cía. Española de Bomberos que pasó, también desde esa misma fecha, a ser dirigida por el bando republicano ${ }^{43}$.

Esta elección extraordinaria terminó por programarse para los días 4, 5 y 6 de marzo de 1938 y como ya lo hemos visto estuvo precedida de un ambiente muy tenso y conflictivo. A través de la prensa local se expresaron algunas manifestaciones de parte de los bandos en conflicto a través de inserciones dirigidas a los electores ${ }^{44}$.

La tendencia mostrada por los electores se orientó a favor de los republicanos lo que hizo pensar a los franquistas en poner término a la elección en forma violenta por lo cual, en la madrugada del día 5 de marzo, hicieron una invasión masiva al local. Sin embargo, no lograron su objetivo y, por el contrario, varios de ellos fueron detenidos por la policía. El enfrentamiento dejó decenas de heridos y contusos e incluso hubo también uso de armas de fuego sin que, afortunadamente, hubiera víctimas fatales. La policía que estaba resguardando el local fue sobrepasada y fue necesaria la venida de refuerzos para poder controlar la situación, luego de una batalla campal, que dejó el local totalmente destruido en su interior. Entre los heridos estaban Adriano Torres, Julio Rodríguez, José Carretero, Juan Ibarra y Jacinto Huerta ${ }^{45}$. Aunque sólo hubo cuatro detenidos, Ramón García Peláez, Álvaro Lavayrú, Adolfo Rincón Iglesias y su hermano Eduardo, los citados a declarar por el juez fueron bastantes ${ }^{46}$.

La situación obligó a las autoridades gubernamentales a tomar medidas, de tal forma que el intendente tuvo reuniones con el vicecónsul a quien le aseguró que no toleraría ese tipo de altercados y, por otro lado, a los nacionalistas les manifestó que no aceptaría que extranjeros hicieran mal uso de la hospitalidad que el país les brindaba. El club permaneció bajo resguardo policial durante los días posteriores ${ }^{47}$.

43 Informe desde el Consulado General de España en Valparaíso al Ministerio de Estado en Madrid, Archivo del Ministerio de Asuntos Exteriores en Madrid, Legajo R-1000, Expediente 2.

44 La prensa local consignó el incidente, el día 5 de marzo, aunque con distinta connotación y nivel de comentarios. Para el conservador diario La Unión no se identifica a los responsables del ataque y señala que no hubo heridos a bala por cuanto se trató sólo de disparos al aire. En cambio, para El Mercurio de Valparaíso, los atacantes son definitivamente del bando franquista y hubo heridos a bala.

45 Diario La Unión (Valparaíso, 5 de marzo de 1938). Diario El Mercurio de Valparaíso (Valparaíso, 6 de marzo de 1938).

46 Diario El Mercurio de Valparaíso (Valparaíso, 6 de marzo de 1938).

47 Idem. 
Los detenidos fueron dejados en libertad el 7 de marzo luego que el magistrado del Primer Juzgado del Crimen analizara la situación ${ }^{48}$.

El embajador Soriano informó a sus superiores peninsulares del ataque efectuado por el bando franquista en el que identificó como líder al ex secretario de la embajada española, Miguel de Lojendio, quien incluso, según su versión, excitaba incluso a matar con tal de ganar la elección. Hace notar que de inmediato apeló a las autoridades gubernamentales quienes «impusieron al Intendente de Valparaíso, enemigo nuestro, medidas de suprema energía que publicaron hasta los diarios derechistas. El local del Centro Español fue custodiado por la policía, presos los agresores y castigada la insolencia de sus jefes con palabras de dura condenación del Intendente. La votación terminó con un gran triunfo nuestro por aplastante mayoría» ${ }^{49}$.

La sangre había llegado al río y el tema trascendió el ámbito local, con lo cual el intendente tuvo que reaccionar en forma apropiada a las exigencias de las autoridades santiaguinas que, al parecer, no estaban dispuestas a comprometer su frente político internacional por el desacierto de un intendente inexperto. Por lo demás, para la fecha el país estaba entrando en plena campaña electoral presidencial y no era bueno generar flancos que pudieran ser explotados por la oposición.

En todo caso, el Gobierno se había mostrado tolerante frente a las acciones políticas llevadas a cabo por el bando franquista que, desde agosto de 1936, contaba con una misión diplomática que comenzó a realizar una activa acción de proselitismo a través de todo el país liderada por dos ex secretarios de la embajada española en Santiago, que renunciaron a sus cargos, Joaquín Pérez de la Rada y Miguel de Lojendio, para generar una instancia de aglutinamiento de las fuerzas franquistas ${ }^{50}$. De alguna forma esta situación presionó a los miembros de la colectividad para que se vieran en la necesidad de asumir una posición frente al escenario que de alguna forma se había trasladado a sus localidades, pese a los intentos de algunos por evitarlo.

Diez años mas tarde, el cónsul general del gobierno de Franco, Ángel de la Mora, explicaba la perdida del control del Centro español, «gracias a la desacertada orientación que a nuestros partidarios se les dio, aconsejándoles procedimientos de violencia, completamente desatinados y fuera de lugar y sin más explicación que pueda disculparlos, que la pasión de aquellos instantes que fácilmente inclinaba a la gente hacia los procedimientos de mano fuerte, como si

48 Diario El Mercurio de Valparaíso (Valparaíso, 8 de marzo de 1938): 9.

49 Informe del Embajador de España en Chile al Ministro de Estado, Santiago de Chile, 11 de marzo de 1938, Archivo de la Fundación Universitaria Española de Madrid, CH 6-8.

50 Almonacid, XXX/30 (Madrid, 2004): 172. 
también aquí estuvieran en guerra civil y hasta se vituperaba y execraba a los que se atrevían a recomendar un poco de serenidad ${ }^{51}$.

La directiva triunfante citó, para comienzos de abril, para proclamar a la directiva triunfadora ${ }^{52}$, a lo que una inserción firmada por «varios socios» respondió que era ilegal por cuanto la elección había sido cuestionada y los antecedentes estaban en los tribunales de justicia ${ }^{53}$. La contra respuesta de los republicanos fue que no había contienda ninguna pendiente en los tribunales sobre la validez de dicha elección y, por consiguiente, la asamblea era un acto legítimo dentro de las atribuciones y deberes correspondientes a la institur ción ${ }^{54}$.

Entretanto, se produjeron algunos cambios en el Consulado al ser llamado, a fines de febrero, Salvador Téllez a continuar sus servicios en el Ministerio ${ }^{55}$. A comienzos de marzo se invitaba, por la prensa, a un almuerzo de despedida al vicecónsul Téllez y familia, «por motivo de su alejamiento del país para incorporarse al Ejército de la República Española» ${ }^{56}$.

Por su parte, los nacionalistas, establecidos en Burgos, creaban un Agencia Consular en Valparaíso y nombraban como su agente consular a quien desempeñaba la presidencia de la Cámara de Comercio, que se mantuvo disidente al régimen republicano, José Osuna. El diario La Unión agregaba que tal designación había sido recibida «por la colectividad española con gran alegría ${ }^{57}$.

Al poco tiempo que se anunció el nombramiento de Osuna apareció también en la prensa un llamado del «Gobierno del Estado Español en Valparaíso» a todos los españoles a inscribirse en el registro de nacionalidad y obtener la cédula correspondiente ${ }^{58}$. La replica de los nacionalistas no se hizo esperar, a

51 Comunicado del embajador Ángel de la Mora al ministro de Asuntos Exteriores, Santiago de Chile, 6 de diciembre de 1948, Archivo del Ministerio de Asuntos Exteriores, Madrid (AMAE), Legajo R 2882, Expediente 90.

52 Diario La Unión (Valparaíso, 7 de abril de 1938): 4.

53 Diario La Unión (Valparaíso, 9 de abril de 1938): 5.

54 Idem.

55 Comunicación del Ministerio de Estado al Vicecónsul Encargado del Consulado General de España en Valparaíso, Salvador Téllez Molina, Barcelona, 23 de febrero de 1938, Archivo de la Fundación Universitaria Española de Madrid, CH 14-11. El comunicado decía textualmente: «Por convenir así al mejor servicio he dispuesto que pase V. a continuar los suyos, con la misma categoría que hoy tiene a este Ministerio, donde percibirá el sueldo personal de seis mil pesetas anuales, asignado a la plaza que va a ocupar en el Presupuesto vigente».

56 Diario La Unión Valparaíso, 10 de marzo de 1938.

57 Diario La Unión (Valparaíso, 29 de marzo de 1938): 5.

58 Diario La Unión (Valparaíso, 31 de marzo de 1938): 5. 
través de un llamado similar, por medio de una inserción encabezada por «Agencia Consular del Gobierno Nacional de España en Valparaíso»"

En agosto de 1938 llegó a Santiago Tomás Suñer para asumir la representación nacional de los franquistas, reemplazando a Pérez de Rada, e iniciar una política de captación a su causa mucho más agresiva, para lo cual contó con el asentimiento o, al menos, la indiferencia del gobierno de Alessandri. Entretanto, la situación militar en España evolucionaba a favor de los nacionalistas quienes, finalmente, lograron el triunfo definitivo con la instauración de la dictadura de Francisco Franco el 1 de abril de 1939.

En todo caso esta definición en España no tuvo mayor incidencia en el particular proceso interno de la colectividad de Valparaíso, por el contrario, se inició un período de tensiones internas que habría de durar muchos años. En cuanto al Centro Español, quedaron los republicanos con el control de la institución y los nacionalistas optaron por agruparse en el Club Español que tenía un local más modesto, hasta que, en 1948, por directa gestión y apoyo económico del empresario Evaristo Peña, dispusieron del amplio y cómodo local de Avenida Brasil, conocido como Palacio Riesco, que mantuvieron hasta la unificación institucional en $1989^{60}$.

Éste era el ambiente que reinaba en la colectividad española residente en el principal puerto de Chile al momento que se comenzó a producir la llegada de los exiliados republicanos.

\section{LA HUIDA}

No pretendemos hacer un análisis de lo que fue la guerra civil, sobre lo cual hay centenares de obras escritas, sino solamente referirnos a cómo vieron,

59 Diario La Unión (Valparaíso, 3 de abril de 1938). La citación agregaba: «Todos los documentos que deban causar efecto en la España Nacionalista y en los países que han reconocido al Gobierno de Burgos, deberán ser legalizados previamente por esta Agencia Consular del Gobierno Nacional de España».

60 Evaristo Peña llegó muy joven, en 1913, a Viña del Mar en donde se desempeñó como empleado en la tienda «El Sol», para luego independizarse y adquirir dicha tienda, en sociedad con Feliciano Formigo. En 1922 se instala solo en Valparaíso con la tienda «La Soriana» que tuvo sucursales en Viña y Santiago. El siguiente paso de Peña fue involucrarse en industrias textiles y participó en la Fábrica de Sedería de Viña del Mar, Fábrica de Rayón de Puente Alto y la Rayonil de Llo Lleo. En su participación en instituciones de la colectividad destacó como presidente de la Cámara de Comercio, presidente del Club Español durante 10 años (1944-1954), director del Banco Español-Chile y del Consorcio Español de Seguros. Ver Aguirre, 1959: 153. 
vivieron o recuerdan, la guerra civil aquellos españoles que llegaron a nuestras costas. Su visión es el testimonio, el recuerdo parcial, de un grupo que no podemos asumirlo como representativo de toda una sociedad pero es la visión y la percepción, con toda la carga de influencias y determinaciones que ello conlleva para sus vidas personales. Sin ser representativo, no se invalida la relevancia que tuvo la experiencia para cada uno de ellos, esto es la historicidad que los hechos poseen en sus vidas.

Para algunos la guerra fue un compromiso ideológico o ético pero también para muchos fue una circunstancia incomprendida y no deseada que determinó enfrentamientos y posiciones de bandos que en ningún caso respondían a posiciones o determinaciones racionales.

Antonio ejemplifica muy bien con el relato de la experiencia de su hermano Cástor los dilemas que planteaba el conflicto cuanto narra la ocasión en que éste se encontraba en las trincheras de Cataluña y se inició un diálogo con el bando contrario y de pronto le preguntaron: «Quién y de dónde eres?» A lo que respondió con su nombre señalando que era de Irún y recibió como respuesta «te conozco, soy fulano de tal» ${ }^{61}$.

Muchos de los excombatientes tuvieron que dejar España y dirigirse a Francia siguiendo la suerte de cerca de 500.000 compatriotas. Allí los campos de concentración improvisados impusieron múltiples penurias a quienes no tuvieron otra alternativa ${ }^{62}$. A Chile llegaron mayoritariamente en el barco francés «Winnipeg», que permitió la llegada de cerca de 2.300 refugiados luego de una exitosa gestión de Pablo Neruda ${ }^{63}$. En grupos menores llegaron también a bordo de las naves «Orbita», «Reina del Pacífico», «Formosa». Otros lo hicieron por vía terrestre desembarcando en Buenos Aires, optando por atravesar la cordillera para llegar a nuestras costas. La reticencia de los refugiados para acudir a los organismos representativos del gobierno de Franco hace difícil conocer el número exacto pero se considera como cifra aproximada los $3.500^{64}$. Sabemos que, de los llegados en el «Winnipeg», quedaron en Valparaíso 650, pero desconocemos cuántos lo hicieron por otras vías. Por lo demás, muchos que llegaron a esta ciudad pronto se fueron a otros lugares; igualmente sabemos de quienes llegaron a otros sitios pero finalmente terminaron estableciéndose en Valparaíso. En todo caso, la presencia del grupo establecido en la ciudad constituyó un aporte significativo, en lo cualitativo, tanto para el colectivo español como también para la ciudad.

\footnotetext{
61 Entrevista a Antonio Narvarte, en Araya, 2006: 198.

62 Ferrer, 1989: 11-28.

63 Carcedo, 2006. Palacios, 1939. Ferrer, 1989.

${ }^{64}$ Lemus, 1998.
} 
Los relatos sobre la huida desde España y Francia son impactantes por las penurias y peligros a los que tuvieron que someterse. Entre tales testimonios podemos rescatar algunos, como el de Pascual quien para protegerse del frío durante la noche, en el campo de concentración francés, cavaba un hoyo en la arena para cubrirse luego con ella. Desde allí logró escapar, junto a un amigo, atravesando un pantano que diariamente investigaron para ver las posibilidades de poderlo cruzar ${ }^{65}$. Sin embargo, la carencia de documentación hizo que su libertad fuera muy breve por lo que muy pronto fueron enviados nuevamente a otro campo de concentración. Allí se les ofreció enrolarse en la Legión Extranjera en donde podían estar cinco años, luego de lo cual podían cambiar nacionalidad e identidad si lo deseaban. También recibieron ofertas para venir a México, oferta que aceptaron llenando unas fichas con sus antecedentes. La demora en salir hizo que algunos huyeran y cuando llegaron las primeras aceptaciones para salir hacia América justamente los aceptados se habían fugado, lo que les dio la posibilidad de hacerse pasar por ellos. Cuando llegaron al puerto, el barco que se dirigía a México ya estaba completo y ante tal situación optaron por subir al que venía a Chile. Algo parecido le ocurrió a Francisco Ramos, dirigente comunista que era buscado por el franquismo, quien originalmente decidió partir a México pero demoró en recuperar a uno de sus hijos que había sido enviado con anterioridad a Francia y tuvo que seguirlo pasando por Marsella para encontrarlo finalmente en París ${ }^{66}$. Esta búsqueda retrasó su llegada al puerto, perdiendo el barco al cual estaba asignado, y frente a tal situación, decidió embarcarse en el «Winnipeg» que salía con destino a Chile. Santiago Meléndez, restaurador catalán, también tenía un pasaje para venir a México pero optó por cederlo a un compañero que necesitaba pasajes para su familia y, finalmente, se embarcó en el «Winnipeg» y su familia se le unió un año después ${ }^{67}$.

Hubo otros exiliados en Francia que pasaron por situaciones extremas en los campos de concentración como verse obligados a comer cucarachas, como ocurrió con el padre de Julia, quien pudo salir rumbo a Chile finalmente a bordo del «Winnipeg» pero su familia sólo pudo unírsele diez años después ${ }^{68}$.

Eloy tampoco pudo venir con su padre, quien también llegó en el «Winnipeg». Se le unió seis años después cuando él ya había formado otra familia. Posteriormente llegaron sus otros hermanos y también su madre ${ }^{69}$. Hubo otras

\footnotetext{
65 Entrevista a Pascual García, Valparaíso, julio 2005.

66 Entrevista a Javier Ramos López, Valparaíso, agosto 2005.

67 Entrevista a Ángel Meléndez i Ceniceros, Valparaíso, octubre 2005.

68 Entrevista a Julia Peral, Valparaíso, octubre 2005.

69 Entrevista a Eloy Infesta, Valparaíso octubre 2005.
} 
familias que nunca pudieron reunirse nuevamente, como fue el caso de Luis, que pudo viajar a Chile a bordo del «Winnipeg» comprometiéndose a traer posteriormente a sus hermanos, pero eso nunca ocurrió. La familia, en España, soportaba los apremios económicos, esperanzada en la gestión de Luis pero éste nunca pudo reunir los recursos para poder cumplir con su promesa. Esta situación planteó un sentimiento de rechazo de la familia española hacia la que se construyó en Chile, que sólo fue superado por las generaciones descendientes. Luis regresó una vez a España pero nunca tuvo la intención de hacerlo definitivamente ${ }^{70}$.

Magdalena salió de España junto a su madre, rumbo a Francia, destinada a un pueblito cercano a Alemania de donde tuvieron que cambiarse pronto a otro lugar; entretanto, su padre estaba en un campo de concentración en donde rechazó la oferta de enrolarse en la Legión Extranjera ${ }^{71}$. Luego de un año logró reunirse la familia e intentaron infructuosamente viajar a México, por lo que finalmente se fueron a la República Dominicana, que era otro de los pocos países latinoamericanos que aceptaba exiliados. Trujillo abrió las fronteras en un afán de mejorar su imagen internacional, «blanquear la raza» y utilizar a los extranjeros como tapón en la frontera con Haití, país con el cual tenía serios problemas $^{72}$. Sin embargo, las posibilidades laborales en ese país eran muy escasas por lo que la familia Antuña procuró reemigrar rápidamente. La ocasión se presentó gracias a los lazos de amistad creados entre el jefe de familia y Víctor Domingo Silva, embajador chileno en la República Dominicana. De esa forma, el grupo familiar llegó finalmente a Chile ${ }^{73}$.

Algunos llegaron muy posteriormente como ocurrió con Isidoro quien, cuando se inició la guerra civil, debió irse a vivir con sus abuelos y luego de tres años regresó con sus padres a Madrid. Se vino a Chile por dificultades laborales y por ser opositor a Franco, lo que le ocasionaba ciertos problemas ${ }^{74}$.

Las separaciones familiares abrieron cicatrices muy sensibles en parte importantes de la sociedad española. El desgarro espiritual es difícil explicar como también complejo dimensionar. De allí lo revelador de la confesión de Pilar que, siendo una niña de 11 años, se vino a Chile sin su madre, a cargo de su abuela: «Nunca olvidaré la despedida, separarme de mis padres y dos her-

70 Entrevista a Gloria, Valparaíso, mayo 2008.

71 Escobar, 2005:248, en abril de 1940 se habían enrolado 6000 españoles en la Legión Extranjera y en regimientos de marcha de voluntarios extranjeros.

72 Llorens, 1975. El texto es un interesante relato sobre los múltiples problemas que tuvieron los españoles bajo la dictadura de Trujillo.

73 Entrevista a Magdalena, Valparaíso, noviembre 2005.

74 Entrevista a Isidoro, Valparaíso, septiembre 2005. 
manos fue algo que jamás logré superar». Sólo al término de la Segunda Guerra Mundial pudo recuperar a sus padres ${ }^{75}$.

Para Vicente y Ana María, de 6 y 5 años respectivamente, la ruta a Chile fue más complicada, ya que fueron enviados a Inglaterra formando parte de un grupo de cerca de 4.000 niños evacuados en mayo de 1937 desde Bilbao, luego de iniciarse los bombardeos sobre la ciudad ${ }^{76}$. El caso de Vicente y Ana María corresponde a los niños que fueron enviados solos a otros países y que posteriormente pudieron reencontrarse con sus padres, pero sabemos que muchos de ellos no tuvieron esa suerte y ni siquiera pudieron regresar posteriormente a su país. Vicente pudo reencontrarse con su madre dos años y medio después cuando pudo regresar a España, pero su hermana Ana María sólo pudo reunirse con su familia en Chile, después de ocho años, cuando hablaba su idioma paterno con mucha dificultad. Fueron miles de niños los que salieron desde España a diferentes países. Además de Inglaterra, se dirigieron también a Francia (22.200), URSS (1.500), Bélgica (3.200), Suiza (245), Dinamarca (105), México (500), etc. ${ }^{77}$. Hubo también casos de niños que fueron recogidos por la embajada chilena abandonados en las calles. Entre los casos más dramáticos resalta el que narra el propio embajador chileno respecto a un niño con ambas manos amputadas:

«Lo encontré en la calle, mordiendo, como un animalito la corteza de un árbol. Le he procurado alimento constantemente y ha sido necesario dárselo en la boca, como a un pajarito. Para huir de la sensación horrenda que me producía la visión de sus manos, levantaba la vista hacia el rostro angelical del pobre niño que sonreía, olvidando la catástrofe irremediable de su vida futura, vida reducida a una inutilidad perpetua y $\sin$ esperanza» ${ }^{78}$.

Por los diversos testimonios recogidos queda claro que, para la mayoría, la venida a Chile fue circunstancial y en todos los casos el conocimiento que tenían de nuestro país era muy limitado. Es sin duda una de las características

75 Entrevista a Pilar Garrote, en Araya, 2006: 180.

76 Vicente Alti narra la situación vivida antes de ser enviado a Inglaterra de la siguiente forma: «Nos salvamos de un primer bombardeo, protegidos en un refugio. Cuatro bombas cayeron en esa oportunidad alrededor de nuestra casa, la que quedó inhabitable. Con la explosión estallaron los vidrios y se incrustaron en muros y muebles, por lo que todo quedó inservible. Dejamos esa casa y nos fuimos a vivir a otra. Al siguiente bombardeo no hubo que lamentar la pérdida de muebles por los vidrios. Una bomba cayó de lleno sobre ella, no hubo muebles rotos ni casa dañada, porque no quedó nada de nada», en Alti Carro, 2006: 14.

77 Idem. 16.

78 Memoria de la Embajada de Chile en Madrid, 19 de abril de 1939, cit. en Romero Pérez: 6-7. 
propias del exilio. Hay premura por salir, de cualquier modo y sin importar el destino.

\section{ADAPTACIÓN E INTEGRACIÓN}

Durante los primeros años varios profesionales exiliados decidieron dejar nuestro país debido a que aquí no se les reconocían sus títulos, y considerando que en México sí eran reconocidos decidieron dirigirse a ese país.

El exilio es una situación de destierro, una emigración no deseada que se espera tenga un plazo determinado. Esa perspectiva hace mucho más difícil la adaptación a la sociedad receptora y se expresa en el síndrome de las maletas listas. Magdalena llegó muy pequeña pero sintió el complejo ambiente impuesto por una emigración no deseada, por ello reconoce las dificultades de la adaptación, advirtiendo que no habían alternativas a la situación ${ }^{79}$.

Rosario reconoce que a su padre, en razón de sus capacidades profesionales, le fue fácil desarrollarse laboralmente, y fue también un activo dirigente dentro de la organización republicana lo cual lo mantenía en permanente participación en la política interna de España. Igualmente, formó parte de la masonería local y gozó de un reconocido prestigio por su notable inteligencia e inquietud cultural que destacaba en el medio. Fue un dirigente activo en diversas instituciones pero mantuvo una postura permanente de rechazo a toda la institucionalidad española oficial en el país. Aunque sus hijos casaron con chilenos, algunos de ellos regresaron a España o como en el caso de Rosario han tenido una vida itinerante pasando temporadas allá y otras acá. Esta última reconoce que su corazón está partido en dos afirmando que «no se puede ser feliz ni en un sitio ni en otro. Siempre está faltando la otra mitad». Sostiene que finalmente ha decidido quedarse en Chile en atención a que aquí están sus hijas y sus ocho nietos aunque siempre lleva consigo la nostalgia, pero su familia es lo primero ${ }^{80}$. Por su parte, Pascual reconoce que si estuviera solo regresaría a España pero está casado con chilena y tiene nietos y bisnietos que no quiere dejar. Hace notar las ventajas que tienen los ancianos en España y que aquí no las poseen. Agrega que viaja a España cada dos años haciendo uso de beneficios que tienen los migrantes mayores de 65 años para viajar durante el invierno europeo lo que les permite estar con su familia española durante tres meses. Pascual tiene allá mas de 30 sobrinos y como 60 sobrinos nietos. Al respecto hace notar que conoció gente que regresó en cuanto se le permitió hacerlo sólo

79 Entrevista a Magdalena Antuña, Valparaíso, noviembre de 2005.

80 Entrevista a Rosario Miranda. Valparaíso, octubre 2005. 
por razones sentimentales por cuanto parte de su familia había quedado en la Península ${ }^{81}$.

Eloy cuenta que algunos de sus hermanos regresaron a España y reconoce que si tuviera veinte años menos también regresaría pero debido a que considera que su actividad laboral, carpintero especializado, ha desmejorado mucho. Dice no echar de menos España aunque sí su música y al mismo tiempo sostiene que le dolería mucho dejar a sus dos hijos por cuanto siempre ha luchado por no separarse de ellos ${ }^{82}$. Bonifacio Martínez, luego de siete años en Valparaíso, en carta a un amigo, reconocía que todavía no se adaptaba, afirmando que «a pesar del tiempo que llevo por estas latitudes no me hago a su ambiente. Por otra parte, dada la mala situación en que se encuentra este país veo muy oscuro el porvenir y el costo de la vida está muy por encima de lo que se puedan imaginar en ésa». Hace notar si que las mujeres chilenas son muy hermosas y simpáticas en lo que según su percepción, dan mil vueltas a las españolas como también en su forma de arreglarse. Se queja, en cambio, que son muy malas cocineras en lo que se nota una gran diferencia frente a las hispanas $^{83}$.

Javier narra cómo en su casa se hablaba que en cuanto muriera Franco regresaban. Del mismo modo, su madre repetía que «si no hubiera tanta agua por medio, volvería». Sostiene que su familia, como otras se aisló en sus casas. Continuaron asumiendo las mismas limitaciones que les había impuesto la guerra: ahorrando luz en forma extrema y distribuyendo los ingresos en forma muy racional de acuerdo a las necesidades básicas de la familia. Finalmente, cuando Franco murió no regresaron. Tanto Javier como su hermano habían formado familia con chilenas. El regreso implicaba terminar con el destierro de los padres pero sus hijos iniciaban por su parte un nuevo destierro. El padre de Javier era Francisco Ramos, un importante dirigente comunista que estaba fichado por el gobierno español y había sido comandante político del batallón de la Unión General de Trabajadores y había sido un activista reconocido en la Universidad de Deusto en Bilbao. En Chile se mantuvo activo y participaba entre los líderes en las instituciones republicanas creadas en Valparaíso. Javier fue a España a visitar tíos y primos y regresó con la sensación de dejar algo que le pertenecía pero con la convicción que lo suyo estaba en Chile sabiendo que tenía nacionalidad española, beneficio que también le dejó a su hijo ${ }^{84}$.

81 Entrevista a Pascual García. Valparaíso, julio 2005.

82 Entrevista a Eloy Infesta. Valparaíso, octubre 2005.

83 Araya, 2006: 228.

84 Entrevista a Javier Ramos. Valparaíso, agosto 2005. 
Isidoro casó con descendiente de españoles, reconoce que se adaptó rápidamente a la ciudad en donde hizo buenos amigos, logró realizarse personalmente y sus tres hijos son profesionales. Hubo un momento en que quiso regresar a España pero, estando allí, se dio cuenta que se habían producido muchos cambios y sus padres ya no estaban. Si bien tenía sus raíces hispanas era al mismo tiempo un extranjero en ese lugar ${ }^{85}$.

Julia demoró mucho en decirle papá a su padre luego de 10 años separados, pensaba que la había abandonado. En ese entonces, con 13 años, sentía rencor por cuanto no entendía la situación. Siempre echó de menos España y quería volver. Su madre nunca volvió y falleció en 1967 con la pena de no haber estado junto a su abuela en su fallecimiento. Quería ser sepultada junto a ella. Su padre quiso reemigrar a Venezuela pero su madre se opuso. Julia dice pensar todos los días en España. En 2000 regresó a su tierra junto a su marido. Recorrió la casa en donde nació y compartió con unos tíos y pudo recorrer España que no conocía. Su retorno a Chile le significó un gran sufrimiento ${ }^{86}$.

Santiago sostenía que no volvía a España mientras viviera Franco. Falleció antes. Su esposa no pudo regresar, pese a sus deseos, por oposición suya. $\mathrm{Su}$ hijo Ángel, que llegó a Chile de 10 años y casó con hija de española, dice haber querido regresar pero sus 5 hijos y las dificultades en España le hicieron desistir. Se manifiesta agradecido de Chile, aquí hizo su vida, pero si hubiera podido habría regresado a España. Afirma que tiene su corazón dividido y que no hay día que no piense en España ${ }^{87}$.

La nostalgia es permanente y para muchos la inestabilidad emocional trae también consigo efectos en sus condiciones de vida material y en su salud. La guerra destruyó familias y provocó la alteración total de la calidad de vida y proyecciones que gestó estados emocionales muy sensibles. Sotera cuenta cómo su padre, que disfrutaba de una posición acomodada, perdió todo. De perito mercantil cambió a fabricante de zapatos. «Trabajó muy duro para alcanzar una cierta estabilidad, en un lugar totalmente desconocido debió velar por el bienestar de su señora, cuatro hijos y una abuelita. Esa presión que lo acompañó siempre debió ser la causante del cáncer que hace veinte años debilitó su salud y acabó su vida» ${ }^{88}$.

Los efectos de desarraigo afectaron incluso a los hijos de los exiliados aun cuando nacieron aquí. Manuel sintió permanentemente una condición de extranjero marginado por la sociedad chilena a la que define como fuertemente

85 Entrevista a Isidoro Molleda. Valparaíso, octubre 2005.

86 Entrevista a Julia Peral. Valparaíso, octubre 2005.

87 Entrevista a Ángel Meléndez. Valparaíso, octubre 2005.

88 Entrevista a Antonio Narvarte, en Rubila Araya, 2006: 199. 
clasista y discriminatoria. Su situación se hizo mas compleja por cuanto como consecuencia del golpe en Chile tuvo que salir de Chile hacia México por cinco años y luego a los Estados Unidos. Al llegar sus padres a Chile como exiliados y haber sufrido el bombardeo de Guernica, su familia vivió una situación difícil pese a que su padre era capitán naval mercante pero no pudo ejercer como tal en Chile. Sus oficios iniciales fueron como comerciante en sociedad dirigiendo un bar, lo que pronto dejó por no sentirse realizado en tales funciones. Luego ejerció como vendedor viajero distribuyendo telas de establecimientos de propiedad de españoles para finalmente decidir irse a Venezuela en donde trabajó como práctico de puerto por cerca de 13 años, período en que sólo vio a su familia durante las vacaciones. Actualmente Manuel vive en los Estados Unidos con la sensación de vivir un segundo período de exilio. Sus dos hijos llegaron a USA a muy corta edad, están casados y para ellos Chile es sólo el país de donde proceden sus padres quienes han decidido quedarse también allíi ${ }^{89}$.

Un caso interesante y dramático es el vivido por la periodista Carlota Goteras, quien llegó a Chile cuando tenía veinte años de edad en 1914, siendo expulsada del país en 1932, durante el gobierno de Arturo Alessandri, acusada de «subversiva». Llegó a Barcelona en donde se desempeñó profesionalmente en el diario La Rambla. Iniciada la guerra civil se incorporó como auxiliar del ejército republicano, llegando a ocupar el cargo de teniente. Posteriormente estuvo en un campo de concentración en Francia durante seis meses hasta que pudo embarcarse en el «Winnipeg» rumbo a Chile, donde el presidente Aguirre anuló el decreto que ordenó su expulsión. El 25 de junio de 1946, nuevamente se determinó su expulsión de Chile por el presidente Gabriel González Videla. Se ocultó procurando evitar la sanción por cuanto ser enviada a España podría poner en peligro su vida. La afectada escribió, en agosto de 1946, desde su escondite en Valparaíso, a Antonio Lezama, representante de la República española en Chile, solicitándole ayuda y haciendo ver que se encontraba enferma y sin poder contar con sus medicinas ${ }^{90}$. Posteriormente, en una segunda carta, de diciembre de 1946, al mismo destinatario, luego de haber superado su problema de expulsión, solicitaba a Lezama le ayudara a conseguir un trabajo como oficinista o dependiente en alguna tienda de compatriotas vinculados a la causa republicana en Santiago ya que «en Valparaíso no hay casas de importancia antifascistas». Hacía notar que vivía a expensas de su hermana ${ }^{91}$. Al parecer la situación de Carlota era más dramática de lo que ella describía por

89 Entrevista a Manuel F. U., Valparaíso, mayo 2007.

90 Archivo de la Fundación Universitaria Española de Madrid, Chi 27-3.

91 Idem. 
cuanto un dirigente de la colectividad española republicana en Valparaíso, ante los requerimientos de Lezama por ayuda para la mujer, sostenía: «esta pobre señora está muy mal de salud, algo o bastante trastornada, económicamente también mal». Hacía notar que se encontraba protegida por la Sociedad de Beneficencia de la colectividad ${ }^{92}$.

\section{CONCLUSIONES}

Queda en evidencia que la colectividad española de Valparaíso se vio involucrada en el conflicto peninsular estimulado por la presencia de los asilados nacionalistas en la época previa al triunfo de Franco, como más tarde con la llegada de los exiliados republicanos. La presencia de los afectados acrecentó la brecha imponiendo una fisura que se prolongó más allá de la muerte de Franco y que sólo los cambios generacionales, y la paulatina desaparición de los directamente afectados por la guerra civil, hicieron posible la reunificación de las instituciones de la colectividad en 1991.

Los conflictos producidos durante el período republicano pudieron haber quedado en un nivel sólo anecdótico, pero la masiva llegada de los exiliados republicanos y su asentamiento en nuestra tierra consolidó la fisura provocada. La historia que iniciaron los exiliados marca un hito importante para la colectividad. Sus relatos son elocuentes en cuanto a las dificultades para adaptarse a la sociedad receptora. Bien sabemos que es también la situación que afecta a los migrantes económicos, sin embargo, la voluntariedad de éstos frente a la involuntariedad que caracteriza a los exiliados marca una gran diferencia.

Es muy difícil pretender evaluar las migraciones. Podemos cuantificar los logros pero ello no significa que tal mecanismo nos entregue indicadores confiables que nos permitan conocer la realidad de lo que ocurre al interior de cada individuo. Los logros materiales son generalmente el resultado de una prolongada vida de extenuante trabajo, austeridad y colmada de privaciones.

Por los testimonios recogidos es palmario que para los exiliados su situación se caracteriza por la inestabilidad y la incertidumbre en grados que no afecta a otros migrantes. A quienes les cupo la responsabilidad del exilio manifestaron su desconsuelo, que muchas veces también lo transmitieron a sus hijos.

Los costos del exilio se llevan en el alma y se expresan en la incapacidad de comprender la realidad y mantener los lazos con el pasado de una manera

92 Idem. 
dependiente sin lograr desprenderse de esa atadura. Por otro lado, el largo período dictatorial de Franco impidió a la generación expulsada poder ser los restauradores de la democracia. Las generaciones posteriores pusieron un manto de olvido a las atrocidades de la dictadura y se mostraron indiferentes y muy poco interesados en reparar las violaciones a los derechos humanos que afectó a sus antepasados.

Es interesante advertir en la sociedad española una suerte de pacto tácito de no escarbar en su historia y enfrentar la situación. Hoy día no hay sanción social para quienes fueron responsables de las atrocidades cometidas durante la dictadura. Los descendientes de Franco son parte de las noticias sociales y es posible encontrar monumentos y todo tipo de testimonios de lo que fue la figura de Franco a través del país.

\section{BIBLIOGRAFÍA}

Aguirre, Luis, Españoles Chilenos, Valparaíso, s/e, 1959.

Almonacid, Fabián, «Españoles en Chile: Reacciones de la Colectividad frente a la República, Guerra Civil y Franquismo (1931-1940)», Revista Complutense de Historia de América, XXX/30 (Madrid, 2004): 149-185.

Alti Carro, Vicente, Me Dejastes Sola Vicente, Viña del Mar, Ediciones Alto Volta, 2005.

Araya Ariztía, Rubila, Arrojos, Dichas y Nostalgias. Vascos en el Valparaíso del Siglo XX, Vitoria, Servicio Central de Publicaciones del Gobierno Vasco, 2006.

Beevor, Anthony, La Guerra Civil Española, Barcelona, Editorial Crítica, 2005.

Carcedo, Diego, Neruda y el Barco de la Esperanza, Madrid, Lavel Ind. Gráfica, SA, 2006.

Escobar, Dina, «La Emigración del Exilio Español a Chile: Los Pasajeros del "Winnipeg". 1939», Dimensión Histórica de Chile, 19 (Santiago de Chile, 2005): 239-301.

Fermandois, Joaquín, Mundo y Fin de Mundo. Chile en la Política Mundial 1900-2004, Santiago de Chile, Ediciones Universidad Católica de Chile, 2004.

Ferrer Mir, Jaime, Los Españoles del “Winnipeg”. El Barco de la Esperanza, Santiago, Editorial Cal Sogas, 1989.

Hobsbawm, Eric, Historia del Siglo XX, Barcelona, Editorial Crítica, 1996.

Lemus, Encarnación, «La Investigación de los refugiados españoles en Chile: fuentes y hallazgos en un exilio de larga duración», Exils el Migrations Iberiques vers l'Amerique Latine, 5 (París, 1998): 273-293. 
Llorens, Vicente, Memorias de una Emigración, Santo Domingo, 1939-1945, Barcelona, ARIEL, 1975.

Morla Lynch, Carlos, Informes Diplomáticos sobre la Guerra Civil Española, Santiago de Chile, Editorial RIL, 2003.

Nocera, Raffaela, Chile y la Guerra, Santiago de Chile, LOM Ediciones, 2006.

Palacio, Solano, El Éxodo, Valparaíso, Editorial Mas Allá, 1939.

Romero Pérez, Elena, Las Victimas Inocentes de un Conflicto: Niños Asilados y Exiliados de la Guerra Civil Española (1936-1939), http//www.memoriando,com/resenas.

Vargas, Juan E., «Carlos Morla Lynch y sus Informes Diplomáticos sobre la Guerra Civil Española», Carlos Morla Lynch, Informes Diplomáticos sobre la Guerra Civil Española, Santiago de Chile, Editorial RIL, 2003.

\section{SPANISH REPUBLIC AND EXILE IN THE END OF THE WORLD VALPARAÍSO, CHILE}

This paper aims to show the repercussions of the Spanish republican experience on the Spanish migrant community in Valparaiso (Chile). It also intends to analyse the adaptation and integration process of the group of Spanish exiles who arrived in this city, after the end of the civil war in their country of origin.

KEYWORDS: republic, immigration, exile, adaptation, integration. 